Supporting Information

\title{
pH-Regulated Reversible Transition Between Polyion Complexes (PIC) and Hydrogen Bonding Complexes (HBC) with Tunable Aggregation-Induced Emission
}

\author{
Sidan Tian, Guhuan Liu, Xiaorui Wang, Tao Wu, Jinxian Yang, Xiaodong Ye, Guoying Zhang, \\ Jinming $\mathrm{Hu}^{*}$ and Shiyong Liu* \\ CAS Key Laboratory of Soft Matter Chemistry, Hefei National Laboratory for Physical Sciences at \\ the Microscale, iChem (Collaborative Innovation Center of Chemistry for Energy Materials), \\ Department of Polymer Science and Engineering, University of Science and Technology of China, \\ Hefei, Anhui 230026, China.
}

To whom the correspondence should be addressed. Email: sliu@ustc.edu.cn (S.L.); hjm85@mail.ustc.edu.cn (J.H.) 


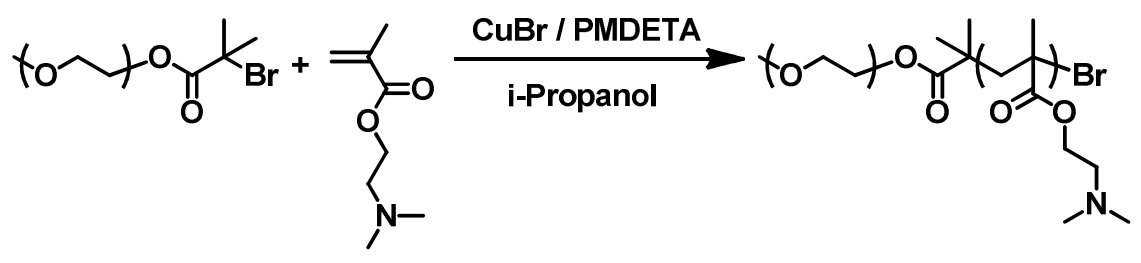

PEG-Br Macroinitiator

DMAEMA
PEG-b-PDMAEMA

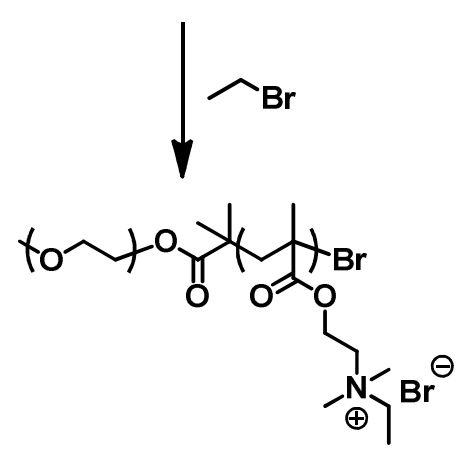

PEG-b-PQDMA

Scheme S1. Synthetic route for the preparation of cationic diblock copolymer, PEO- $b$-PQDMA, via ATRP and subsequent quaternization reaction. 


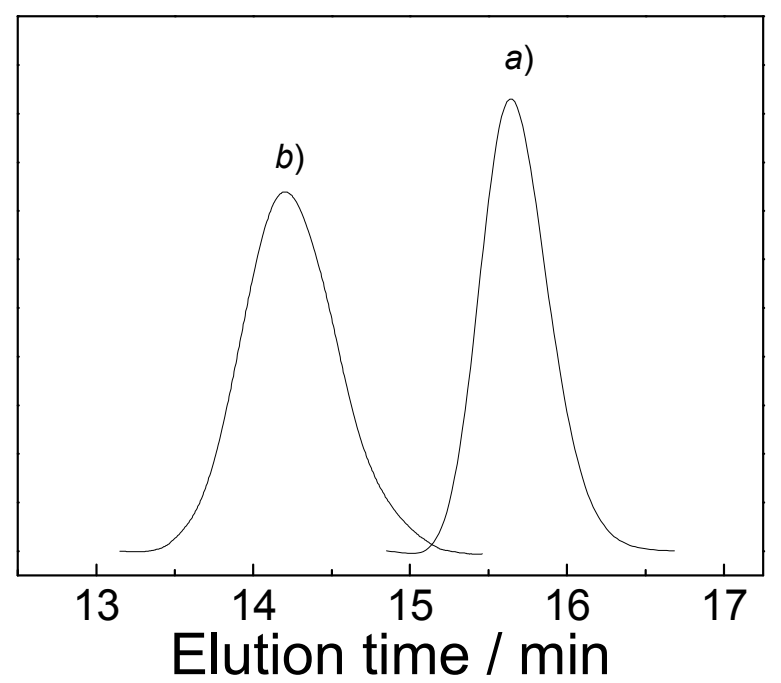

Figure S1. GPC traces recorded for (a) PEO- $B r$ macroinitiator and (b) PEO- $b$-PDMAEMA diblock copolymer precursor before quaternization. 


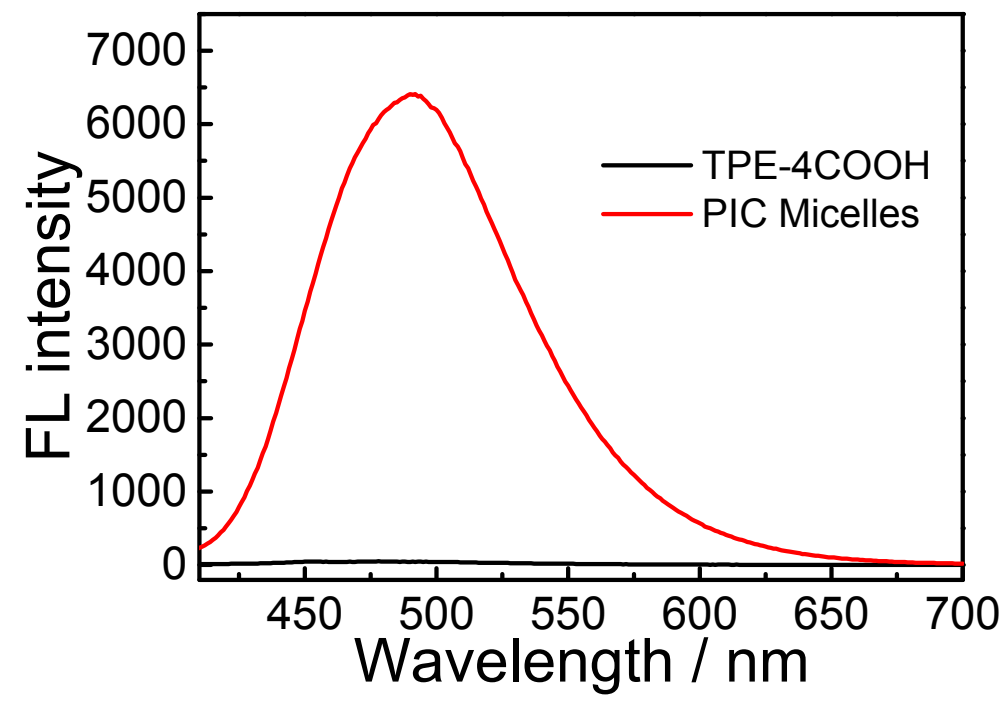

Figure S2. Fluorescence spectra $\left(\lambda_{\mathrm{ex}}=390 \mathrm{~nm}\right.$; slit width: Ex. $\left.5 \mathrm{~nm}, \mathrm{Em} .5 \mathrm{~nm}\right)$ obtained at pH 8 for TPE-4COOH solution and PIC micelles assembled from PEO- $b$-PQDMA and TPE-4COOH at the $\left[\mathrm{QDMA}^{+}\right] /\left[\mathrm{COO}^{-}\right]$molar ratio of $1: 1$. The TPE-4COOH concentration was fixed at $0.25 \mathrm{~g} / \mathrm{L}$ in both cases. 

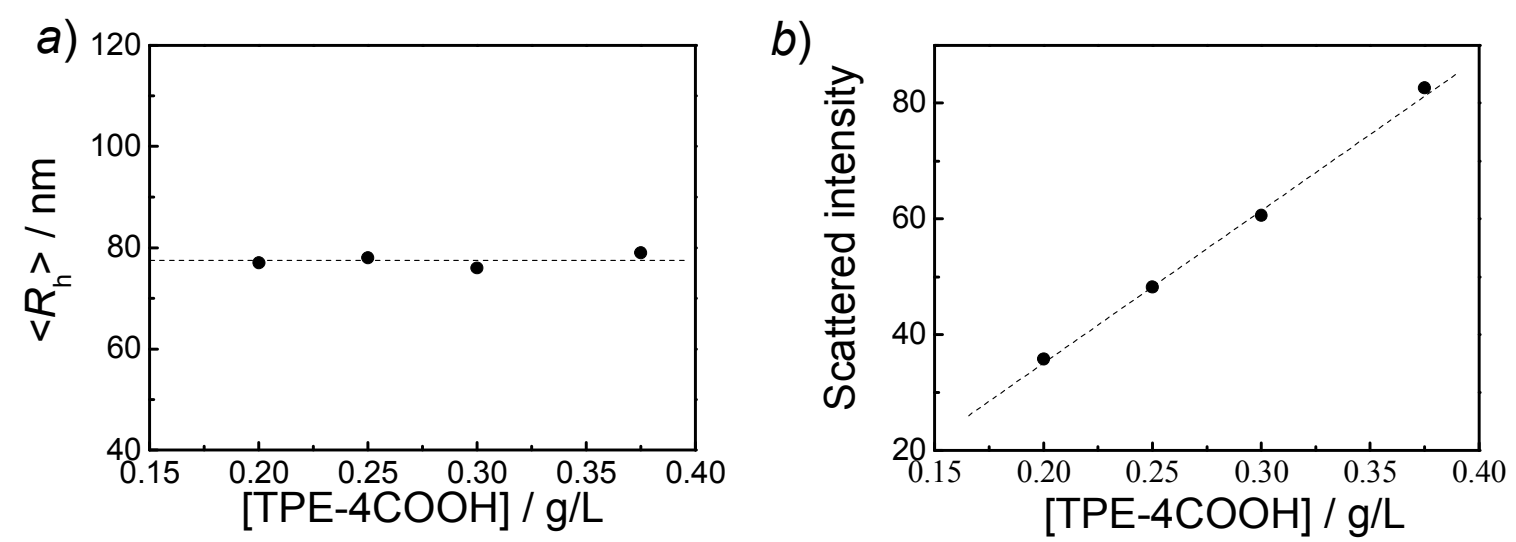

Figure S3. Concentration dependence of (a) intensity average hydrodynamic radius, $<R_{\mathrm{h}}>$, and (b) relative scattered intensity recorded for aqueous solutions of PIC micelles assembled from PEO- $b$-PQDMA and TPE-4COOH at varying concentrations $\left(\mathrm{pH} 8,25{ }^{\circ} \mathrm{C}\right)$. The molar ratio of $\left[\mathrm{QDMA}^{+}\right] /\left[\mathrm{COO}^{-}\right]$was fixed at $1: 1$. 

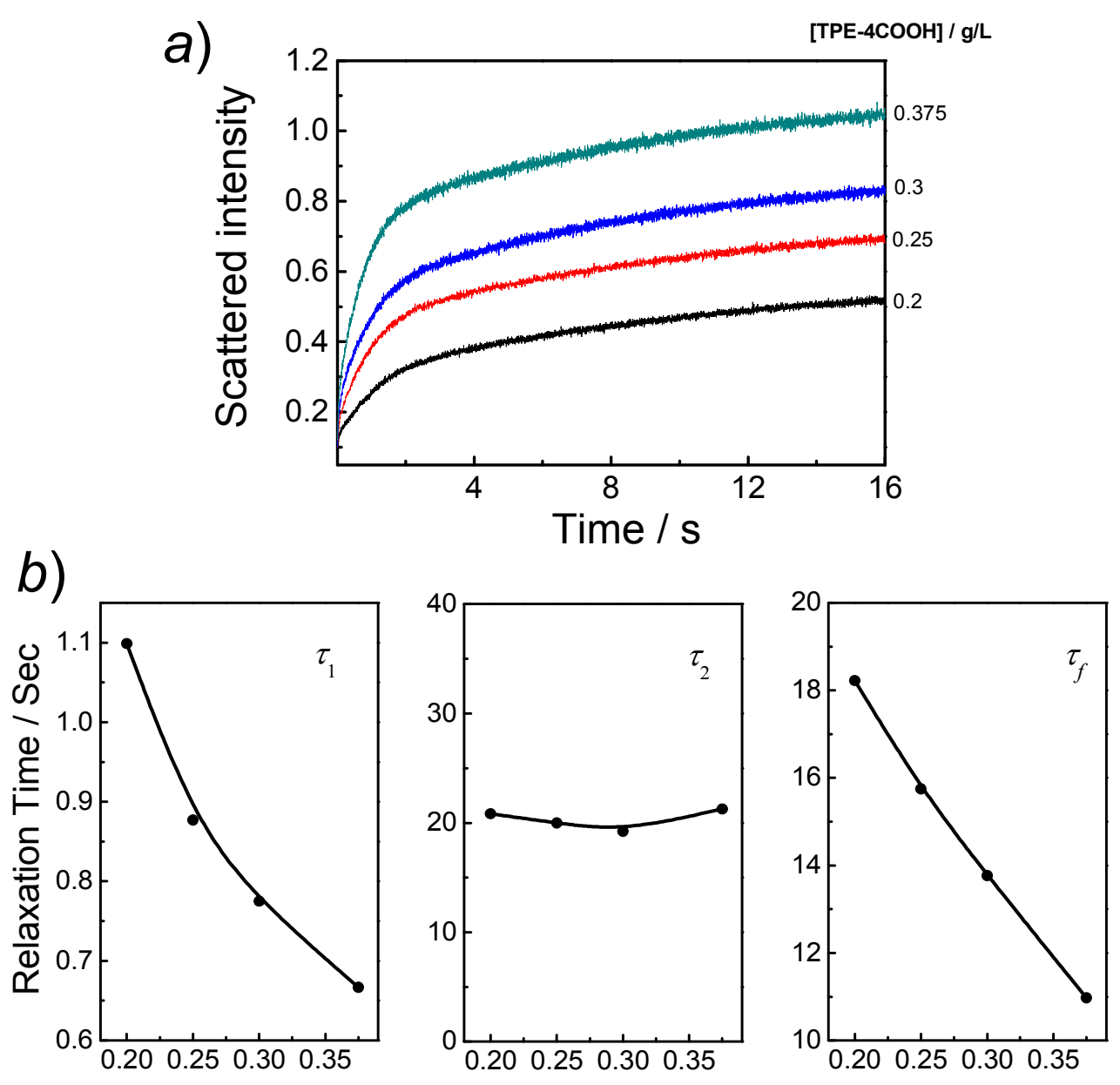

$[\mathrm{TPE}-4 \mathrm{COOH}] / \mathrm{g} / \mathrm{L}$

Figure S4. (a) Time dependence of the scattered light intensities recorded upon stopped-flow mixing of the aqueous solutions ( $\mathrm{pH} 8,25^{\circ} \mathrm{C}$ ) of PEO- $b$-PQDMA and TPE-4COOH at varying concentrations $\left(\left[\mathrm{QDMA}^{+}\right] /\left[\mathrm{COO}^{-}\right]=1 / 1\right.$ in all cases $)$. (b) Double-exponential fitting results of kinetic traces recorded upon stopped-flow mixing of the aqueous solutions $\left(\mathrm{pH} 8,25^{\circ} \mathrm{C}\right.$ ) of PEO- $b$-PQDMA and TPE-4COOH at varying concentrations. The $\left[\mathrm{QDMA}^{+}\right] /\left[\mathrm{COO}^{-}\right]$molar ratio was fixed at $1: 1$ in all cases. 


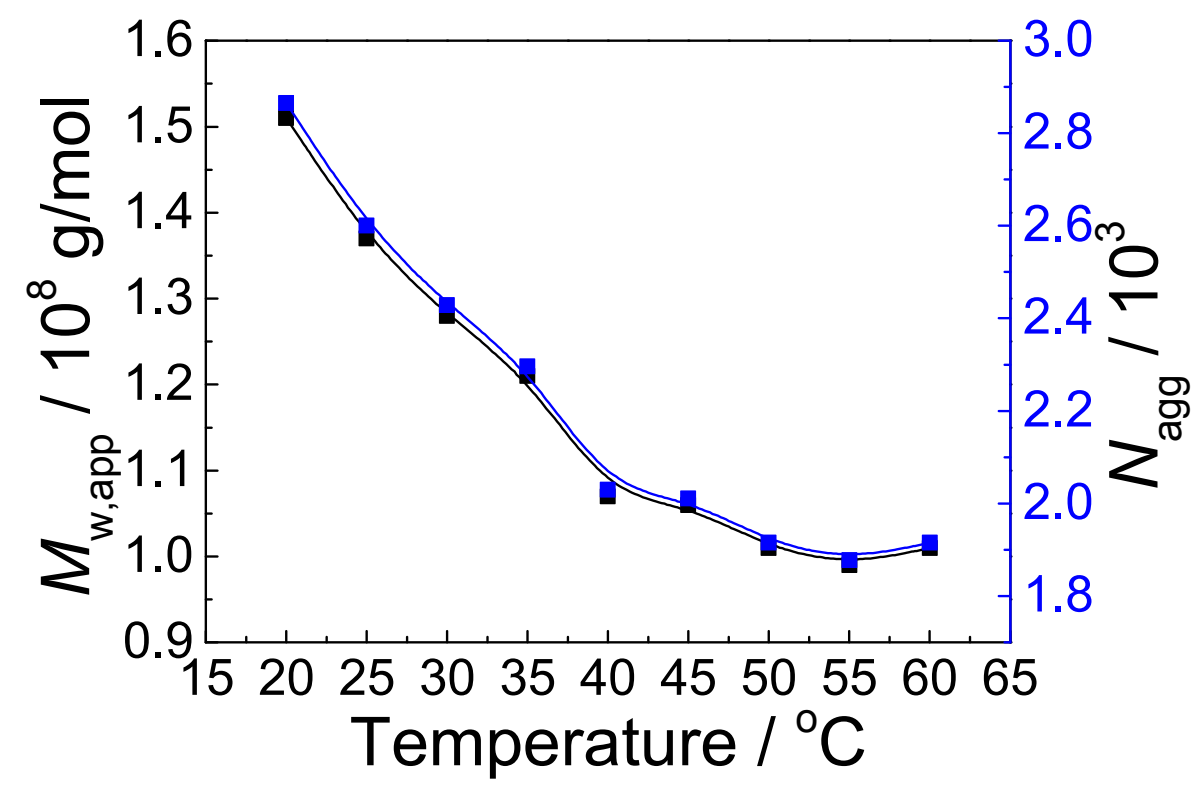

Figure S5. Temperature dependence of the apparent molecular weight, $M_{\mathrm{w}, \text { app }}$, and aggregation number, $N_{\mathrm{agg}}$, of PIC micelles $(0.1 \mathrm{~g} / \mathrm{L})$ of PEO- $b$-PQDMA and TPE-4COOH. The molar ratio of $\left[\mathrm{QDMA}^{+}\right] /\left[\mathrm{COO}^{-}\right]$was fixed at $1: 1$.

Note: The aggregation number, $N_{\text {agg, }}$, was calculated based on the assumption that negatively charged TPE-4COO ${ }^{-}$moieties were stoichiometrically neutralized with cationic $\mathrm{QDMA}^{+}$residues in the PEO- $b$-PQDMA diblock copolymer within the PIC micelles. 

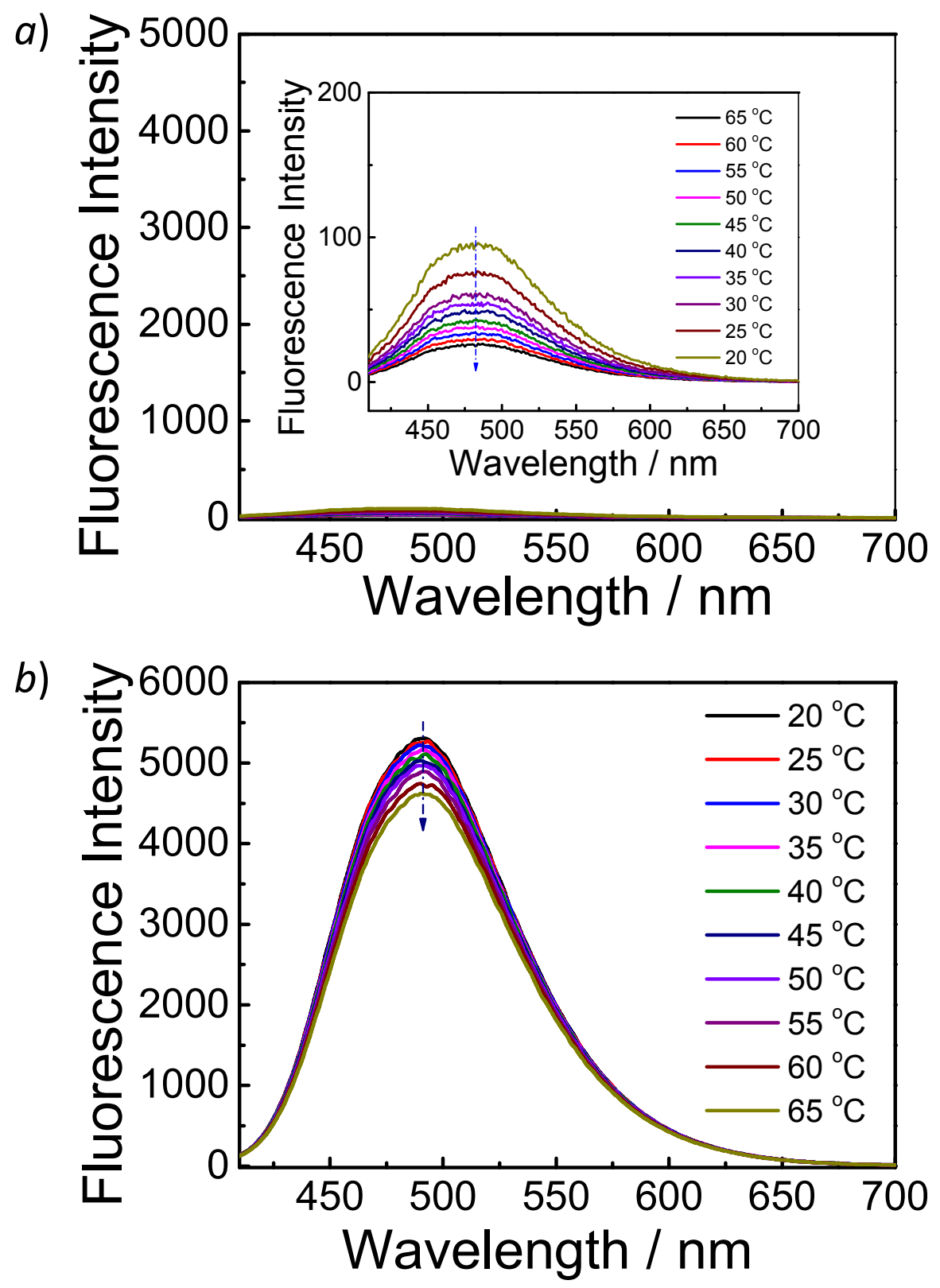

Figure S6. Temperature-dependent fluorescence emission spectra $\left(\lambda_{\mathrm{ex}}=390 \mathrm{~nm}\right.$; slit width: Ex. $5 \mathrm{~nm}$, Em. $5 \mathrm{~nm}$ ) for the aqueous solution of TPE-4COOH $(0.25 \mathrm{~g} / \mathrm{L})$ at (a) $\mathrm{pH} 8$ and (b) $\mathrm{pH} 2$, respectively. 


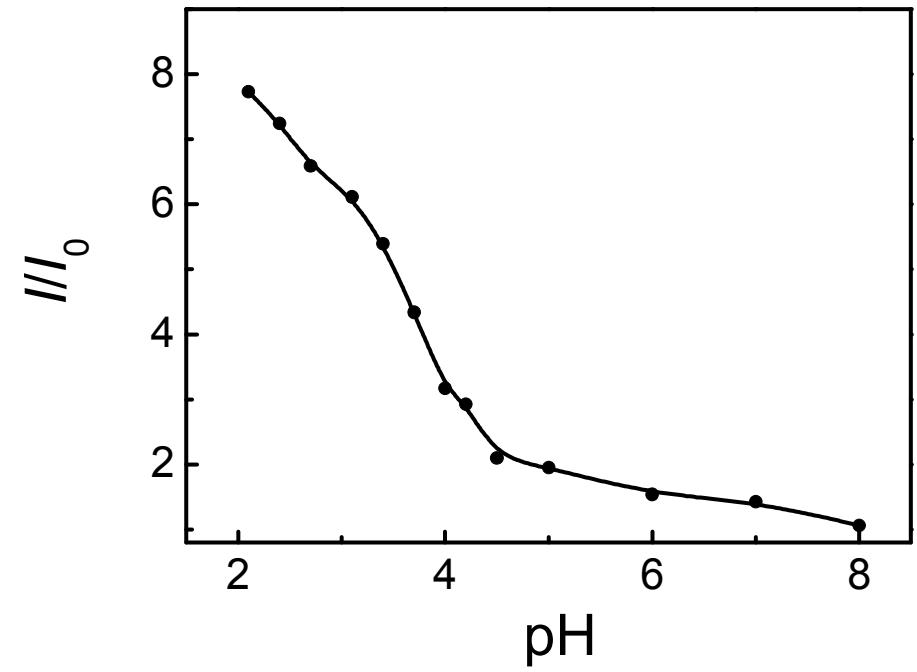

Figure S7. Normalized fluorescence intensities at $490 \mathrm{~nm}\left(\lambda_{\mathrm{ex}}=390 \mathrm{~nm}\right.$; slit width: Ex. $5 \mathrm{~nm}$, Em. 5 $\mathrm{nm})$ recorded for aqueous solutions of PEO- $b$-PQDMA and TPE-4COOH at varying $\mathrm{pH}\left(25^{\circ} \mathrm{C}\right)$. The molar ratio of $\left[\mathrm{QDMA}^{+}\right] /\left[\mathrm{COO}^{-}\right]$was fixed at 1:1 and the TPE-4COOH concentration was fixed at $0.25 \mathrm{~g} / \mathrm{L}$ in all cases. 
a)

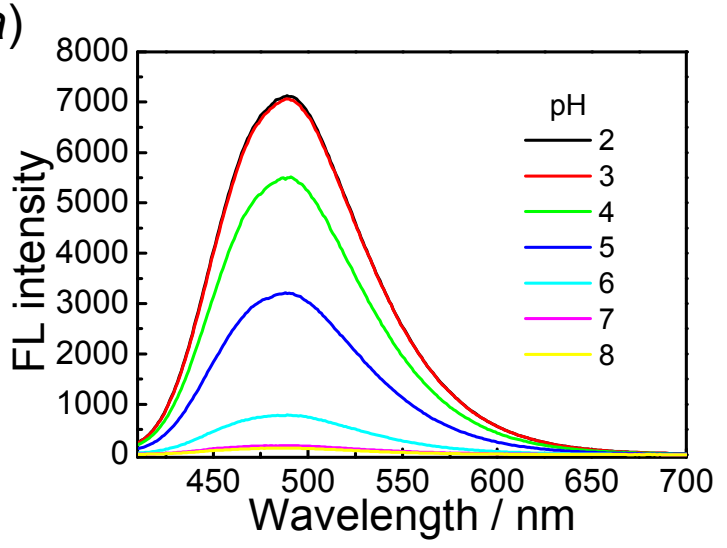

C)

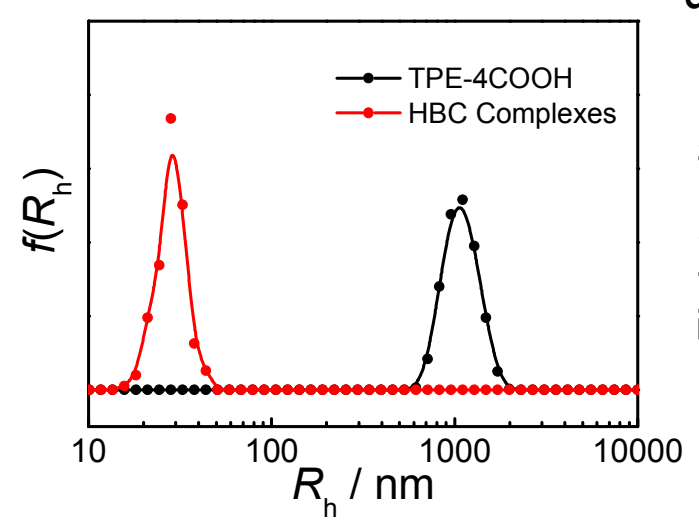

b)

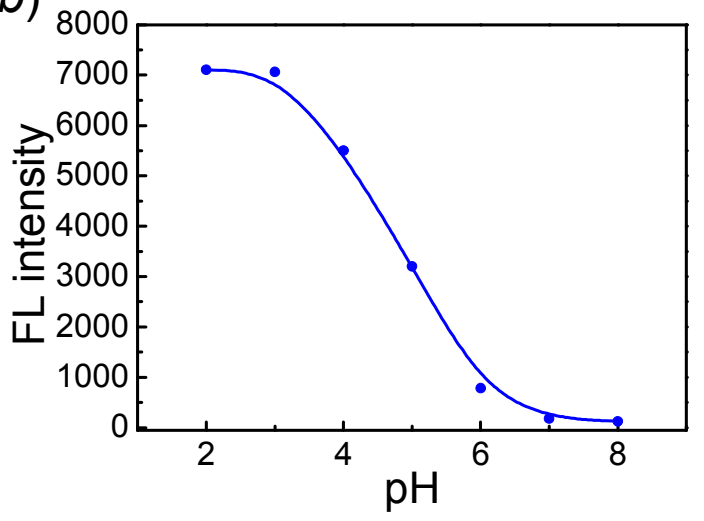

d)

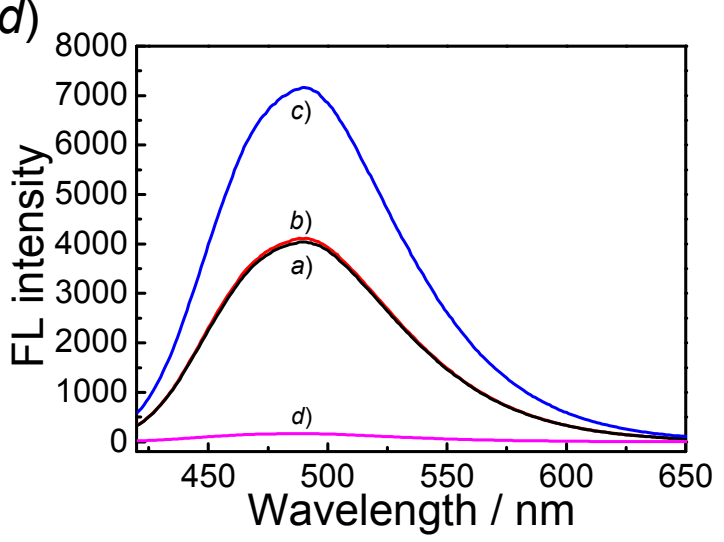

Figure S8. (a) Fluorescence emission spectra and (b) fluorescence intensity changes $\left(\lambda_{\mathrm{ex}}=390 \mathrm{~nm}\right.$; slit width: Ex. $5 \mathrm{~nm}, \mathrm{Em} .5 \mathrm{~nm})$ recorded for TPE-4COOH aqueous solutions $(0.25 \mathrm{~g} / \mathrm{L})$ at varying pH. (c) Hydrodynamic distributions of aqueous solutions of TPE-4COOH and PEO- $b$-PQDMA/TPE-4COOH mixture $\left(\left[\mathrm{QDMA}^{+}\right] /[\mathrm{COOH}]=1: 1\right)$ at $\mathrm{pH} 2$. In both cases, the TPE-4COOH concentration was fixed at $0.25 \mathrm{~g} / \mathrm{L}$. (d) Fluorescence emission spectra recorded for aqueous solutions ( $\mathrm{pH}$ 2) of (a and b) PEO-b-PQDMA/TPE-4COOH mixture at the $\left[\mathrm{QDMA}^{+}\right] /[\mathrm{COOH}]$ molar ratio of $1: 1$ and (c and d) TPE-4COOH (a and c) before and (b and d) after filtration with $0.45 \mu \mathrm{m}$ filter membranes. In all cases, the TPE-4COOH concentration was fixed at $0.25 \mathrm{~g} / \mathrm{L}$ prior to filtration. 